Dossier : Literaturas y disidencias sexuales

\title{
Una narración de las fisuras: lo queer de la infancia en la novela $V$, de Mariana Docampo
}

\author{
A narration of the cracks: queering Childhood in Mariana Docampo's novel V
}

Maria José Punte

DOI: https://doi.org/10.24215/25457284e117

Universidad Católica Argentina - Instituto de Investigación

de Estudios de Género, Universidad de Buenos Aires,

Argentina, Argentina

majo.punte@gmail.com

iD http://orcid.org/0000-0002-2425-6129

Recepción: 02 Marzo 2020

Aprobación: 30 Abril 2020

\section{RESUMEN:}

La obra de Mariana Docampo se ha ido desplegando desde un primer volumen de cuentos, Al borde del tapiz (2001), hasta su más reciente novela, $V(2017)$, siguiendo una trayectoria que sigue el punteo de ciertas obsesiones. Como los pasos del tango que ella tan bien domina, sus textos hacen un dibujo que adquiere volúmenes en el espacio. Esas derivas hacen visible una cartografía queer, o lo que Elisabeth Freeman denomina una "erotocartografía”. Parte del extrañamiento que producen sus textos, en los que se cruzan desconcertantes preocupaciones por los devenires científicos contemporáneos con sus posibles conexiones cosmogónicas y religiosas, puede tener que ver con una mirada infanceada, una que deforma y desrealiza lo narrado, no tanto a partir del papel (des)configurador de la rememoración, sino de aquello torcido que puede estar radicado en la infancia.

PALABRAS ClaVE: Literatura argentina, Infancias Queer, Mariana Docampo, Novela.

\section{Abstract:}

Mariana Docampo's work has developed from her first volume of short stories, Al borde del tapiz (2001), to her most recent novel, $V(2017)$, following a trajectory that is punctuated by certain obsessions. Like the steps of tango that she masters so well, her texts make a figure that acquires volumes in space. These drifts make visible a queer cartography, or what Elisabeth Freeman calls an "erotocartography". Part of the estrangement produced by her texts, in which disconcerting concerns about contemporary scientific developments intersect with their possible cosmogonic and religious connections, may have to do with an infantile gaze, one that deforms what is narrated, not so much from the (dis)configuring role of remembrance, but from that which is twisted and may be rooted in childhood.

KEYWORDS: Argentine Literature, Queer Childhood, Mariana Docampo, Novel.

\section{INTRODUCCIÓN}

Comencé a descubrir fisuras en distintas partes. Comprendí que no sólo hay áreas que favorecen los pasajes y facilitan su detección sino que las personas con capacidades ampliadas pueden realizar tránsitos desde cualquier sitio. Se trata de un reacomodamiento de la percepción. Mi práctica me llevó a lugares impensables.

\section{Mariana Docampo, Tratado del movimiento}

Prácticas de la escritura que funcionan como ejercicios anotados en un cuaderno. Cuadernos que se van sumando y que revelan una figura de autora inclinada sobre un trabajo de descubrimiento en el que la preocupación por el funcionamiento del sistema cósmico es propuesta como una tarea minimalista: se concentra en la observación de una hoja o de una brizna de pasto para poder entender los movimientos trans-estelares. Lo mínimo y cercano hablando de lo máximo o (todavía) inalcanzable. La obra de Mariana Docampo, nacida en Buenos Aires en 1973, ${ }^{1}$ sigue ese periplo resumido en el epígrafe, una especie de conclusión que se lee hacia el final de su cuarto libro Tratado del movimiento (2014), texto que se anuncia 
como novela. La estructura de este texto y la textura de su lenguaje resultan desconcertantes para el lector que todavía acepta el pacto narrativo propuesto por el género de la novela. Podría ser leída, al igual que su quinta novela $V$ (2017), como un relato de ciencia-ficción. El extrañamiento que propone su Tratado del movimiento puede ser adjudicado a la elección de un punto de vista situado en una subjetividad ajena a la especie humana (¿un extraterrestre?), pero capaz de realizar traducciones y de entender el funcionamiento de los lenguajes. Es más, se trata de una subjetividad que desde esta reflexión enunciada como la observación científica de un ecosistema identificable con el planeta tierra, se propone como una descripción de una cronografía evolutiva, tanto biológica como cultural: la que da como resultado al mundo que habitamos.

Los textos de Mariana Docampo parecen ir buscando esas fisuras que permiten reacomodar la percepción, tal como se propone la voz narradora del Tratado... En ese camino, van agudizándose algunas de las preocupaciones que no es tan difícil percibir como una constante. Luego de un primer volumen de cuentos, Al borde del tapiz (2001), en el que prima un tono evocativo y nostálgico, con su novela El molino (2007) alcanza una narración que da forma densa -aunque contenida- a una pesquisa todavía centrada en los vínculos establecidos entre las formas microsociales (la familia, el matrimonio) con las dimensiones de lo nacional y macro-histórico (la situación del país durante la dictadura cívico-eclesiástico-militar de 1976-1983). En su tercer volumen, $\mathrm{La}$ fe (2011), vuelve a la narración breve, cada vez más centrada en indagaciones existenciales, psicológicas y teóricas, lo que ofrece una forma de cartografía de la constitución de las subjetividades contemporáneas, en la medida en que se configuran fuertemente condicionadas por el medio ambiente y los contextos en que están insertas. Aparecen los temas recurrentes de su obra: la maternidad, los trastornos psíquicos, la infancia en su función de período formador, las relaciones lésbicas y la fluidez sexual, la ecología y los actuales desajustes medioambientales, las creencias mediante las que se sostienen los distintos sistemas de pensamiento.

En este trabajo, la mirada se centrará en la última de sus novelas, $V$, un texto extraño pero muy acorde con cuestiones tan actuales como la ecología y los cambios producidos en el medio ambiente por la especie humana, cruzados con una reflexión sobre los límites y posibilidades de la noción de "sujeto". Justamente, es la idea de "especie" la que es reconsiderada en esta forma de viaje que se presenta como una traslación más allá del tiempo y del espacio. De alguna manera, recupera algo del modo narrativo que estaba presente en su primera novela, El molino, pero lo desrealiza al pasarlo por el tamiz de algunas de las inquietudes que dan una forma más conceptual que narrativa al texto mencionado antes, el Tratado del movimiento. El modelo de la "novela familiar" reaparece nuevamente en $V$, pero desfigurado a través de una trama que evoca al género de la ciencia ficción, con algunos toques de fantasy. En realidad, lo que propone este texto es una reflexión sobre nuevas posibilidades de dar inteligibilidad a la experiencia cronotópica de las subjetividades actuales, ya no sujetadas a condicionamientos rigurosos en lo que respecta tanto al género sexual, como a las fijaciones espaciales y temporales. Y también permite imaginar modos inéditos de vincularse con las diversas especies que habitan el planeta. No se trata de fantasías distópicas, sino de posibles salidas a algunas de las encerronas en las que se encuentra la especie humana hoy, colándose por esas fisuras que buscan ser liberadoras.

La infancia se ve aquí como un vértice por el que se fuga esta subjetividad, tras la búsqueda de otros posibles caminos o desviaciones de los trazados fuertemente disciplinadores que la condicionan. Y es punto de toque, también, de discursos biopolíticos que definen desde el comienzo de cada vida cómo debe ser estipulado lo vivible. El momento de la infancia es el núcleo al que se remiten estos discursos, de modo que, al ponerlo en discusión, se hace indispensable volver a esta instancia formadora. Pero también porque allí reside una potencia que es en sí queer, que habla de torsiones y de caminos alternativos, no estipulados ni todavía domesticados, de una temporalidad a la que se buscan domeñar pero que es observada desde la mirada adulta como aún puro presente. Esa infancia que está ubicada en un pasado (visto desde lo que sería la situación actual de cada observador/a), es una constancia de otras existencias posibles y, por lo tanto, subsiste como un elemento espectral. En ese sentido fantasmal es que resulta asimismo queer, según la propuesta de la teórica Katrhyn Stockton, como se verá a continuación. 


\section{LA INFANCIA, UNO DE ESOS "LUGARES IMPENSABLES"}

En un texto breve que está en el primer volumen, Al borde del tapiz, se da una definición de una infancia que puede ser la propia o la de cualquiera. No es tan difícil no reconocerse en ella, a pesar de presentarse como un hilo conductor que atravesará los siguientes textos de Docampo. La cita es extensa para ser cita, pero ocupa una página, desorientando la lectura del libro en tanto que libro de "cuentos". Tampoco puede ser considerada un microrrelato. Es un fragmento que preanuncia un recurso al que la autora volverá en su última novela, $V$, el de intercalar textos más breves que interrumpen el fluir de la narración. Producen el efecto que tienen las postales en un relato de viajes, al abrir ventanas y congelar determinados momentos o imágenes.

Luego de ser introducido por el título "Absolutos", el fragmento dice lo siguiente:

Era el tiempo de gigantes y absolutos. Mi humanidad entera cabía en el abrazo de mi madre, mis lágrimas llegaban a Dios sin mediaciones, las horas transcurrían lentamente en una vaporosa ilusión de inmortalidad. Era el tiempo en donde el grito de mi padre estallaba en el cielo y delimitaba su imperio, el tiempo de los cuentos interminables a orillas de mi cama, la edad en la que cada uno de mis miedos tenía consuelo bajo la tibia presión de una mano. Era el tiempo de los juegos, y del tedio pronunciado durante las horas de la siesta. Era el tiempo de mi infancia, un círculo evaporándose (2001, p. 13).

La infancia se define, aquí, a partir de su vínculo con la temporalidad, como una manera específica de entender y codificar el tiempo. Es un tiempo evanescente, porque no llega a ser medido desde una conciencia infante en su total exactitud. La experiencia temporal parece estirarse, justamente ante esa imposibilidad de cronometrar, calcular, separar. Es un tiempo cíclico (algo que el texto subraya mediante la anáfora, volviéndolo poético), que adquiere volúmenes a través de los modos en que esta subjetividad se vincula con los otros cuerpos o con los objetos, así como con las actividades que le están reservadas: los juegos, la siesta, los cuentos. El tiempo "infanceado" es lo que los griegos llamaban el tiempo de Aión, del acontecimiento que adviene, que siempre está llegando; una forma de eterno presente. ${ }^{2}$ De ahí que esta voz lo defina como un tiempo de "absolutos". Si, por un lado, se trata de un tiempo que se ensancha hasta la imposibilidad de conmensurarlo -de "cuentos interminables", de "ilusión de inmortalidad", de "tedio pronunciado"-, la otra cara de esta magnitud es su anulación o disipación: es "un círculo evaporándose”. No falta ironía, como era de esperar, en la utilización del término "absolutos": el ansia de totalidad y plenitud se sabe, vista con la perspectiva que ofrece la distancia, tan perecedera como frágil. Lo que se evapora son las certezas, más que la infancia.

Por otro lado, el fragmento abre con una mención espacializante particular, la que al pensar a los sujetos infantes en sus conexiones con el entorno concibe este período de la vida desde la miniaturización. Les niñes son seres pequeños o empequeñecidos. Se sienten ínfimos frente a les otres, esos "gigantes". El agigantamiento se manifiesta en su faceta positiva en el abrazo de la madre, o negativa en el grito imperioso (intemperante) del padre. El vínculo cronotópico, entonces, exige ser pensado bajo otros parámetros ante la constatación de que una posible entrada a la compresión de lo que es la infancia tiene más que ver con cómo se conciben las relaciones espacio-temporales, que con las posibilidades de comunicar esa experiencia. ${ }^{3}$

La imaginación espacializante, aquella que piensa a les sujetes como resultado de las relaciones con el entorno, ya que somos moldeados emocionalmente a partir de esos contactos (como desarrolla en su teoría de las emociones Sara Ahmed, 2015), cuando se confronta con las infancias no puede no considerarlas sino desde lo queer. Así es como las piensa la teórica Kathryn B. Stockton, quien afirma que detrás de todo infante hay una posibilidad de lo queer: "Scratch a child, you will find a queer" (2004, p. 278). Si bien ella considera esto desde los despliegues ficcionales acerca de las infancias, es decir, a partir de las presencias de cierta queerización que es posible rastrear en las ficciones (contemporáneas y no tanto, como aquellas que se van gestando a partir del período victoriano), lo cierto es que su idea del infante queer abre perspectivas para entender a la infancia en general, además de todo aquello que se busque concebir en relación con lo no normativo. 
La espacialidad vuelve a jugar un rol importante en esta definición de lo infante, porque lo específico de esta instancia tiene que ver con la noción de crecimiento, de su detención o ralentización, es decir, de las velocidades. El siglo XX, dice Stockton en su libro The Queer Child (2009), se obsesionó con la idea de controlar el crecimiento de los menores, en vistas a preservar una concepción de la inocencia que está vinculada antes que nada con percepciones adultocéntricas. Por eso resultan tan sorprendentes, por momentos, las acciones y los motivos de les menores; el hecho de ser inesperados, imprevisibles, erráticos, produce toda clase de ansiedades en les adultes, hasta generar incluso una iconografía violenta a la que se considera particularmente desestabilizadora. La figura unida a dicha concepción de la inocencia es lineal y ascendente: sólo se crece en una dirección. Adquiere una fuerte matriz idealizante: se apunta hacia un futuro que funcionaría como guía o tutor, camino del cual conviene no apartarse. No seguir esa línea supone un crecimiento detenido, una trayectoria torcida o desviada, un corte abrupto e indeseado. Stockton recupera la idea de crecimientos hacia los costados ("sideways"), de movimientos laterales que se producen en torno a les sujetes y ofrecen otras alternativas ante una idea lineal y unívoca de crecimiento.

Michel Foucault ya había pensado a la infancia desde las fuertes restricciones espaciales, mediante el sistema de escolarización que seguía el modelo médico-militar, pero también en el hogar burgués que fue reduciendo más y más la libertad de movimientos de les menores. La sexualidad pasa a ser un efectivo dispositivo de control, una tecnología del cuerpo puesta al servicio de optimizar no solo la distribución de esas corporalidades en el espacio, sino también su uso eficiente. Foucault nos hace ver que se empieza a hablar mucho de sexo en paralelo a habitar el espacio de otra manera, en dinámicas que son proliferantes: "El espacio de la clase, la forma de las mesas, el arreglo de los patios de recreo, la distribución de los dormitorios (con tabiques o si ellos, con cortinas o sin ellas), los reglamentos previstos para la vigilancia a la hora de acostarse y de dormir, todo ello remite, del modo más prolijo, a la sexualidad de los niños" (2010b, p. 30). Surge la figura del "niño masturbador" como una de las posibilidades de lo monstruoso, que genera toda una batería de recursos discursivos y materiales emparejados con la idea de perversión, entre ellos la tecnología de la confesión, que es lo que da origen a una "cartografía pecaminosa del cuerpo" (2010a, p. 180). La masturbación, convertida en problema pedagógico y médico, va a llevar a la sexualidad (sobre todo en la figura del adolescente masturbador) al campo de la anomalía (p. 186). En consecuencia, a una espacialidad acotada, se corresponde una corporalidad que fantasea con la superación de los límites y que los desborda.

En sintonía con estas ideas y para la misma época, René Schérer y Guy Hocquenghem desarrollan en su libro Co-ire. Album sistemático de la infancia (1976) de manera ensayística en base a textos literarios la noción de descentramiento mediante la idea del "rapto". Ellos afirman de modo asertivo, pero no exento de ironía: "El niño está hecho para ser raptado, de esto no cabe duda. Su pequeñez, su debilidad, su hermosura invitan a ello. Nadie lo duda, empezando por él mismo" (p. 9). Con esta metáfora del rapto, los autores invitan a pensar en aquello desestabilizador que les adultes proyectan sobre les infantes, algo que se aplica -antes que nada- a las propias certezas sobre el orden familiar y social. La fantasía del rapto, esa "idea fascinante" tan presente en los sueños infantiles, apunta contra la seguridad cotidiana, el “calor del hogar”. La seducción, mezcla entre lo temido y lo deseado, radica precisamente en la violencia. El rapto, a diferencia de la fuga, es rápido y preciso, es irreversible y se funda en una "afirmación de sí" (p. 11). Actúa en contra de la "viscosidad de los compromisos familiares y su lentitud" (p. 10), del "envolvente pensamiento parental, del lento camino de la pedagogía" (p. 11). La lógica del rapto tampoco es la del secuestro, en donde el niño es robado en tanto que moneda de cambio entre adultos, es decir, no deja de ser una prenda del mantenimiento del orden social. El rapto, por el contrario, introduce un tercer término que altera la lógica de la simple alternancia entre vida y muerte; hace emerger algo distinto (p. 14). Es la puerta abierta a lo desconocido, lo monstruoso, lo inhumano (p. 16). Coinciden con el pensamiento de Michel Foucault cuando dicen que el rapto se opone a la "enfermedad social e individual del sedentarismo" para las que se movilizan todas las técnicas de poder y encierro que este describe. En la institución de encierro, el niño siente todo su desamparo y dependencia. De ahí su añoranza de escapada, del afuera. Esa "apropiación familiar del niño" es una ilusión invencible de la cual somos víctimas. 
El niño vuelve a ser lo que es en la medida en que es raptado, es decir, desvinculado de la construcción familiar a la que ellos denuncian como temporal, artificial, ficticia y producto de la ideología. En suma, la definición que dan Schérer y Hocquenghem de la infancia está cargada de dinamismo: "Pero no nos hagamos ilusiones; jamás están allí donde se los busca; la infancia es siempre una forma de ponerse fuera de alcance, de subvertir la lógica adulta mediante la rapidez de sus desplazamientos" (p. 43).

Retomando el fragmento del comienzo, "Absolutos", aparecen allí in nuce tanto las temáticas como la tesitura narrativa que Docampo va a desplegar de manera más pormenorizada en sus siguientes textos, sobre todo en su primera novela, El molino. Son varias las problemáticas que atraviesan como nervaduras este relato, a la vez denso y minimalista. En un lugar central, sin embargo, podría decirse que el texto propone una indagación sobre esa idea de familia cuestionada por Schérer y Hocquenghem, aquella que tiende a esencializar o naturalizar una determinada construcción que debería ser percibida tan contingente como ideológica. Si bien la novela no pone en escena ningún tipo de rapto, ya que la familia en cuestión permanece amalgamada a lo largo de lo narrado y tampoco se abandona la idea de familia en sí, hay momentos en donde es posible percibir esas "fisuras" de las que habla el epígrafe inicial. La dinámica de los “tránsitos" ya está presente aquí, así como la estructura fragmentada y dispersa, que de alguna manera responde a que la historia contada fue sometida a un proceso de fuerzas tanto centrífugas como centrípetas, algo a lo que se alude mediante la figura del molino y su estructura giratoria.

La novela cuenta la historia de una familia católica numerosa, formada por la pareja parental, ocho hijos pequeños, los abuelos y la tía Eugenia. El tiempo narrado transcurre entre los años 1979 y 1982 cuando la familia se instala en la localidad de Zárate, provincia de Buenos Aires, a causa del trabajo del padre. La focalización está puesta en la mirada de Juana, que entonces tendría unos seis años, por lo que la historia se encuentra desrealizada, pierde sus contornos nítidos. Algunos recuerdos son, por momentos, borrosos; y ciertos hechos narrados no pueden haber sido enunciados por esa narradora, sino en todo caso haberles sido narrados (algunos son consignados en 1974, año en que nace: dice haber nacido el 28 de diciembre de ese año). Por otro lado, el punto de vista que organiza esas rememoraciones se sitúa en un momento ubicado en la adultez entre el año 2004 y el 2005, lo que explica la obsesión por consignar las fechas que va punteando todo el relato y demarcando un sistema que casi se propone como un diario íntimo. Ese punto de vista es el que produce la fisura mencionada, en un doble sentido. Abre una mirilla hacia ese pasado al que se desea organizar; abre una opción a la estructura familiar tradicional heternonormativa.

La familia ya no será más un epicentro de la novela $V$, aunque el desmontaje de su estructura sigue siendo puesto en acto. Está más en un cuestionamiento del sentido biopolítico en el que se suele encuadrar la noción de familia, en tanto que sustento de un determinado orden social. La familia se presenta como el primer ámbito en donde se produce una intensa medicalización del sujeto, un sometimiento al aparato médico que termina siendo uno de los rostros de lo siniestro. La necesidad que apunta a producir sujetos aptos y eficientes en tanto que parte fundante de una dinámica reproductiva, termina convirtiéndose en una obsesión por eso que Penélope Deutscher retoma de Lee Edelman, la idea de "futurismo reproductivo" (2019), lo que conduce a producir los efectos contrarios a los deseados: sujetos enfermados por el sistema, convertidos en desechos, cuya única salida posible es renegar de todas estas constricciones y hacer estallar las fronteras de lo conocido. Un más allá del nombre, que implica no sólo un más allá del sujeto sino también de la especie; un deslizarse de la historia personal hacia una temporalidad cósmica.

\section{V: DINÁMICAS DEL DESPLAZAMIENTO}

Una mujer, Verónica, siente un dolor intenso al atravesar un puente mientras está de visita en la ciudad suiza de Lucerna. Ese dolor funciona como una caída de/en la materialidad. Le impide seguir; la obliga a quedarse sentada en ese lugar. Significa, por un lado, la percepción del propio cuerpo y su reconocimiento como tal; por el otro, produce un desprendimiento de ese mismo cuerpo en la medida en que es vivido como 
un extrañamiento de aquello que se considera la normalidad. El dolor pone en evidencia algo, pero a la vez funciona como causa de posibles mutaciones. Cuando Sara Ahmed se refiere al dolor, sostiene que en primera instancia toda sensación dolorosa implica la reconstitución del espacio corporal y una reorientación de los cuerpos con respecto a aquello que produce el dolor. Los cuerpos y los mundos, nos dice, se materializan o toman forma al producirse el efecto de frontera, de superficie, o de permanencia en los contactos mutuos. La intensificación de las sensaciones de dolor obliga a reconsiderar ese contacto (Ahmed 2015, p. 54). El personaje de $\mathrm{V}$ es un buen ejemplo de este funcionamiento corporal. El dolor la fuerza a reorientarse, lo que la conduce a una forma de "reseteo". No queda del todo explicitada la razón de esta necesidad, aunque luego algunas pistas se darán al ser contada su infancia. El efecto que produce esta reubicación adquiere traslaciones a "lugares impensables" (Docampo 2014, p. 93), como propone el epígrafe tomado de su volumen anterior. Tal vez porque $\mathrm{V}$ sea una de esas personas con "capacidades ampliadas", aunque nada denote en ella algún tipo de carácter excepcional.

A partir de ese instante, empieza a ser narrado el periplo de una subjetividad que se des-sujeta, que comienza a multiplicarse en numerosos avatares. En ese acto, pierde el nombre, pasa a ser denominada como "V". Esa deriva lleva a este sujete -que dejará de ser mujer y pasará a ser hombre, animal, planta, bacteria, sustancia interestelar, máquina-, a la pérdida de todo estado o al pasaje por diversas gradaciones de la materia. No solo se desrealiza la dimensión espacial, dado que $\mathrm{V}$ se muestra en espacios inimaginables y remotos desafiando la causalidad. El vector temporal tampoco responde a coordenadas del todo reconocibles. Las traslaciones que experimenta $V$ nos llevan a tiempos tan disímiles como el Medioevo, el pasado remotísimo del planeta tierra a la existencia humana en él, un futuro plausible y distópico, o la postal detenida de una tierra sólo transitada por animales.

Esos avatares no son infinitos, nos aclara la voz narradora. Son múltiples y variados; atraviesan un espectro de posibles vidas en todos sus grados de dolor y de placer. No obstante, hay una $\mathrm{V}$, un vértice hacia el que estas vidas confluyen. Existe una memoria o, al menos, el esfuerzo de una subjetividad por recoger como si fuera un manojo de experiencias los rastros de todas estas traslaciones. En ese sentido, se vislumbra un deseo narrador que intenta explicar mediante la historia familiar la serie de desprendimientos del yo que acontecen a ese sujete y que dan pie a una narración significante. La novela $V$ puede ser leída como un relato de ciencia ficción o como un manifiesto futurista de lo que es posible lograr si se sigue experimentando con los diversos estados de la conciencia, algo que parecía resumir la extraña propuesta del Tratado del movimiento. También evoca una fantasía muy ligada a las dinámicas de la ficción, la que permite vivir muchas vidas a través de lo narrado. En una entrevista que da la autora dentro del ciclo En la Biblioteca dirigido por Irene Chikiar Bauer, Docampo despeja una duda intertextual al decir que el nombre de su personaje le fue inspirado por la película del director polaco Krystof Kieslowski La doble vida de Verónica (1991). Le interesaba esta idea de una mujer que podía vivir dos avatares de una existencia paralela. En su novela, Verónica se expande a muchas vidas, muchas más que dos, porque lo que Docampo desea explorar en ella de modo explícito es la posibilidad de cuestionar tanto las nociones de sujeto único, como de tiempo lineal. Como constata la protagonista, "se vio a sí misma en simultáneo en otras dimensiones" (2017, p.19).

Otra fuente de inspiración podría ser la novela Orlando: una biografía (1928) de Virginia Woolf. Solo que, en $\mathrm{V}$ la narración biográfica queda pulverizada más que parodiada. Aquello que esta novela busca es una forma de concebir a un posible sujeto no sujetado por categorías tales como unicidad, sexo o especie. No se limita en hacer un avance que atraviese la frontera del género sexual, sino que va hacia una subjetividad que está más allá de la especie. El trabajo de desmontar el relato (auto)biográfico apunta en esa dirección. La crítica a la familia nuclear heteronormada que era la premisa de su primera novela, El molino, reaparece como uno de las causales de la dinámica entrópica que hace implosionar al sujeto aquí. Una vez más, esto se encuentra enunciado hacia el final de Tratado del movimiento, bajo el título "Explicaciones para la comprensión del reducto Alfa, Plano 1 , sociedad y núcleo familiar primigenio" (2014, p. 75 . El subrayado está en el original). Como si fuera un examen a cargo de un observador externo a la especie humana, se plantea el papel de la estructura familiar 
en la constitución subjetiva que puede ser aplicado a lo que sucede con V: "Cada actor familiar cumple un rol en relación al neonato redentor. Puede pasar que haya fallas en la formación del nato o bien, fallas en su educación. En ese caso, el neonato deberá reencarnar" (p. 76). La referencia a las "familias santas", cuyas características se desarrollan entre las páginas 76 y 79 del Tratado..., apuntan al modelo familiar religioso que aparecía narrado en El molino y que aquí es definido como "sobrevivientes del antiguo régimen" (p. 77). Este "sistema tradicional" al que se ve en proceso de atomizarse, ofrece sin embargo la posibilidad de generar una nueva forma de infancia, los "niños índigos", redentores de la humanidad, conectores del antiguo y el nuevo régimen, "surgidos en el nuevo sistema multiparental y protosexual" (p. 77). Mucho más no se aclara sobre estos "niños índigos", pero vemos en acción la propuesta mediante el personaje de V.

$\mathrm{V}$ (erónica), por otro lado, parece ser el resultado acabado de una versión disfuncional de la familia. El texto consigna su pre-historia cuando se remite a lo que sería una forma todavía reconocible de relato de infancia. Se dice de V que fue concebida en enero de 2007 en el barrio porteño de Núñez. Sus padres son médicos. La madre, más precisamente, especializada en neonatología. Esto provoca que su persona quede a merced de una intensa medicalización y permanente control por parte de la pareja parental. Ya desde antes de nacer, desde su estadía en el útero materno, recibe los impactos de lo que sienten y proyectan sobre ella sus padres. La madre vive con angustia ese proceso; el padre se va tornando cada vez más agresivo hasta terminar convirtiéndose en lo que la narración define como un monstruo que maltrata a la niña sin aparente razón. El nacimiento de $\mathrm{V}$ se produce en un ambiente claramente hostil. La voz narradora constata que todo lo que viva de ahí en más, “terminará siendo fundacional de su personalidad. Eso fosilizará sus reacciones y emociones" (p. 32). De tanto temer que se enferme, las ansiedades paterno-maternas provocarán que la niña se convierta en una enferma crónica. A los tres años de V, nace un hermano. Esta niña, que ya había sido sometida a intervenciones quirúrgicas desde los dos años, será diagnosticada a los tres de tener episodios psicóticos. Luego del nacimiento de su hermano es que $\mathrm{V}$ comienza a entrenarse para practicar bilocaciones y metamorfosis. El lenguaje que adquiera va a ser "reducido, de poca complejidad, con grandes zonas de incertidumbre" (p. 37).

A pesar de este intento de explicación racional para lo que le sucede al personaje, el lenguaje médico quedará subsumido en la trama posterior de las traslaciones del personaje de V. No es la primera vez que en Docampo será parodiado este lenguaje, así como su sistema de pensamiento. Ya había un ejemplo en el relato "La fe", que integra el volumen del mismo título. Tiene que ver con la lectura de la biopolítica que atraviesa toda su obra y que hará eclosión en su última novela, con una solución tan poética como sugerente. Lo cierto es que $V$ pasará a ser una niña que vive en una permanente disociación entre dos espacios: la clínica y el encierro en su cuarto. De ahí que comience a practicar formas de tránsito, de pasaje, estados de latencia o de suspensión: "A veces, si sale al jardín y camina por un sendero que está marcado recto en la tierra hacia el árbol, varias $\mathrm{V}$ se desunen y andan separadas. Algunas trepan al árbol, otras caminan. Algunas incluso, interrumpen su lazo con la materia y atraviesan el muro" (p. 41). Fruto de su observación, $\mathrm{V}$ comienza a ver esos desprendimientos también en los otros seres, como por ejemplo en los pájaros, referencia constante. Por otro lado, $V$ es el punto nodal de esas multiplicaciones que se dan de manera simultánea, en un tiempo que no avanza. Todas las secuencias confluyen en ese punto, definido como el "0, nexo que las articula" (p. 45). No se trata de una identidad infinita, nos aclara la voz narradora, "pero sí tan vasta que $[V]$ se ve obligadx a hacer agrupaciones temporales de su yo para ordenar su experiencia” (p. 45).

La novela de Docampo expone de manera literal eso que Kathryn Stockton proponía como figura para pensar lo queer de la infancia, una concepción del crecimiento que no es lineal, sino que se despliega hacia los costados, generando movimientos impensados e irregulares. Hay una historia en el personaje de $\mathrm{V}$ que comienza en la infancia. O, por el contrario, nuevamente se recurre a la infancia para encontrar la explicación a eso que empieza a suceder en un momento preciso en Lucerna, ya que una narración tiene que comenzar en algún punto, aunque luego se abra como un abanico en varias direcciones. El primer movimiento que practica la niña toma la forma de un desdoblamiento: 
Se podría decir que $V$ tiene dos infancias, una en la clínica, otra encerrada en el cuarto de la casa. No hay manera de conectar una y otra; ella misma no puede determinar con exactitud cuándo está en la clínica y cuándo en la casa. Padre y madre son para ella entidades separadas. Puede que se despierte un día en la clínica, y al día siguiente en el cuarto de su casa, y sucede a veces, que estando en el jardín en plena observación del pájaro, está, a la vez, en la habitación, recibiendo las lecciones de la madre (2017, p. 39).

A esta práctica comenzará a sumarse la de las "desapariciones”, que consiste en "traslados físicos" o "tránsitos" de carácter tanto espacial (a "otros espacios dentro del mundo") como temporal ("a estados de latencia o suspensión”). Y esto va ocurriendo a la niña de manera natural, nos aclara la voz narradora. El resultado es eso que la voz define como "desprendimientos".

La idea de simultaneidad con la que coquetea esta concepción subjetiva apunta, por un lado, a repensar nociones ligadas con la temporalidad. Pero también está presente lo que la geógrafa Doreen Massey propone como el deseo de plasmar una "nueva imaginación geográfica", vale decir, modos de comprender y dar forma al espacio en estos tiempos contemporáneos caracterizados por las traslaciones constantes, los achicamientos de las distancias, y por la intensa aceleración temporal de los traslados. En su propuesta, las dimensiones de tiempo y espacio se suponen mutuamente, sin que la una esté subordinada a la otra. Massey desea sacar a la noción de espacio de una concepción estática y, al mismo tiempo, hacer notar cómo se encuentra imbricada de modo íntimo con el vector de la temporalidad. En ese vínculo, ella propicia las ideas de heterogeneidad, relacionalidad y contemporaneidad. El espacio es el producto de interrelaciones (2014, p. 115), sostiene. Es también la esfera de la posibilidad de la existencia de la multiplicidad (p. 102) en la que coexisten distintas trayectorias. También piensa al espacio en constante proceso de formación, un devenir que no está ni acabado ni cerrado. Esa imaginación geográfica adquiere su forma en la novela de Docampo, que hace visibles otro tipo de tramas espacio-temporales, nuevas cronotopías.

Por su parte, enfocada desde la historia del arte, Graciela Speranza está pensando el funcionamiento de las ficciones que intentan plasmar estos nuevos lazos temporo-espaciales. Ella lo hace acuñando la idea de "cronografías", para referirse a las imágenes y relatos que se producen en un "tiempo sin tiempo" o de un "presente embriagado de presente" (2017, p. 15). Se trataría de un tiempo topológico, imposible de separar de ciertas determinaciones espaciales. Speranza se confronta en su propuesta teórica con cuestiones que Docampo coloca en el centro de su novela, la del comportamiento humano frente a las otras especies, sus gestos de dominación sobre los ecosistemas que están conduciendo a una rápida destrucción del planeta que habitamos junto con tantas especies animales y vegetales, y que amenaza con su posible destrucción o con cambios tan irreversibles como traumáticos. Speranza nos recuerda que estamos en lo que ya se denomina "Antropoceno", una era geológica caracterizada por el antropocentrismo que hace peligrar la convivencia inter-especies. La narración propiciada por $\mathrm{V}$, al descentrar la subjetividad humana y ponerla en contacto con las demás especies, con los elementos geológicos y con otras posibilidades para su cadena de ADN, ofrece esas imaginaciones o variantes para fantasías de supervivencia.

Más allá de esta preocupación ecológica que campea en el texto, también es posible pensarlo como un cuestionamiento de concepciones lineales del tiempo, lo que configura otro de sus rasgos queer. La dislocación temporal que estaba presente en El molino, se acentúa aquí de manera proporcional con la dinámica centrífuga ya puesta en acto en esa primera novela, con lo que se queeriza también esta forma de género textual. Tal y como hace notar Elizabeth Freeman, de lo que se trata es de escapar de la doble trampa tendida entre un tiempo lineal y otro circular, polaridad en la que suelen moverse las narrativas sobre las temporalidades, incluso dentro del feminismo. El tiempo lineal que remite al discurso de lo nacional, también es fuertemente criticado por teóricos como Lee Edelman cuando piensa a la infancia y cuestiona la matriz de futuridad con la que se la suele vincular. Freeman, por su parte, hace una crítica a ese tiempo ligado a la construcción comunitaria que se propone desde el Estado y que parece sólo poder moverse en una dirección ineluctable. Pero tampoco le cuadra el tiempo cíclico de lo doméstico como alternativa al tiempo lineal. El recorrido que ella hace a través de sus análisis de ficciones, busca ir alejándose de la "crononormatividad", vale 
decir, tanto del "tiempo dañado" de la Historia, uno que se entiende como progresivo y que está en la base de la noción de genealogía, como de otro que se vincula con la intimidad doméstica y con la stasis. Lo que ella define como una "erotohistoriografía" se hace cargo, más bien, de las "arritmias" que interrumpen tantos relatos, salidas que se manifiestan desde ciertos modos de la resistencia, así como de la demora (ese "temporal drag"). Esto da como resultado narraciones mediante las que se busca expresar junto con lo traumático, tanto el éxtasis como el gozo, elementos que para ella debería ser esenciales a una historiografía queer que recupere los residuos de afectos positivos: idilios, utopías, memorias táctiles. En esto coincide con la teoría de las emociones de Sara Ahmed, que recupera como "sentimientos feministas" afectos tales como el asombro y la esperanza; el orgullo, reivindicado por las políticas queer, pero también la capacidad de acomodarse, de hacerse un lugar. Se trata, para ella, de entender cómo las emociones nos afectan y moldean nuestros cuerpos (tanto las negativas como las positivas), y de concebir nuevas poéticas que sirvan para nombrar la fluidez de las subjetividades contemporáneas.

\section{Estética DE LA CONTIGÜIDAD}

En el relato "La fe", antes mencionado, la voz narradora del cuento concluye de la siguiente manera: "Quiero decir: no hay cosmos. Hay conectores que articulan sistemas. Y cada objeto es portal y conector de otro sistema. Ahora circulo entre las personas, con animales a mi alrededor. Estoy conectada con el Todo" (Docampo 2011, 90). Este bien puede ser el programa literario que viene atravesando toda la obra de Docampo en general, pero también una definición para la novela analizada aquí en particular. En un sistema que no se cierra, sino que va conduciendo al lector a través de un portal a otro y a otro, o de una dimensión a la siguiente, la narración se dispara en numerosas direcciones y desborda las formas. Permite imaginar una figura que parafrasea al universo, no sólo en dirección hacia un espacio exterior infinito, sino hacia el corazón de la materia. Es un viaje interestelar e intramolecular porque lo que ha logrado es superar la linealidad impuesta por una temporalidad cronométrica. Los vínculos familiares pueden ser leídos también de adelante para atrás, desatendiendo cualquier tipo de genealogía.

Algo de esa estructura "radicante" (para usar el término de Nicolás Bourriaud), se veía en el cuento del mismo volumen que lleva por título "La raíz", que indagaba -antes que nada- en la cuestión del dolor, a partir de la idea fallida de maternidad. ${ }^{4} \mathrm{La}$ "raíz", imagen que obsesiona a esta madre al borde de la locura, es "Una fisura por donde huía la luz" (p. 12), una hendidura de la conciencia que permite la fuga de un mundo al que se percibe como mera apariencia. Algo así le sucede a V(erónica) quien, al caer en medio de ese puente de Lucerna, se deja arrastrar por el flujo que carcome todo asidero espacio-temporal. De ahí en más, empieza su periplo que por otro lado no es solo espacial, ya que va de atrás hacia adelante, de arriba hacia abajo, de la intimidad hacia los bordes. Parece responder a esta figura del radicante que propone Bourriaud, que proviene del mundo vegetal y se refiere a las plantas que crecen en todas direcciones, como la hiedra, y que se agarran a la pared en múltiples puntos. Sus raíces crecen según el avance y se desarrollan en función del suelo que las recibe. Por eso, para Bourriaud, la condición de radicante califica a un sujeto contemporáneo que se encuentra atormentado entre la necesidad de un vínculo con su entorno y las fuerzas del desarraigo (2018, pp. 58- 59). $\mathrm{V}$, de modo análogo al sujeto radicante propuesto por Bourriaud, existe bajo la dinámica de la errancia y por los límites del circuito que delinea (p. 63).

El acompañamiento constante de los animales también supone una queerización de la subjetividad, en la medida en que permite torceduras o desvíos con respecto a la especie. En cierto sentido responde a la idea que plantea Stockton cuando habla de la infancia y el "intervalo animal", bajo la figura que se suele adosar como compañía natural de los personajes infantes, muchas veces bajo la forma del perro (2009, pp. 89-97; 2004, p. 299 y ss.). Pero también en las ideas de Gabriel Giorgi que piensa al animal como umbral biopolítico, espacio privilegiado para las indagaciones de la cultura. La proximidad entre lo humano y lo animal abre una zona de proximidad que permite la interrogación ética a la vez que genera un horizonte de politización, nos 
dice Giorgi en su libro Formas comunes (2014, p.14). El texto de Docampo bien puede ingresar en alguna de las series que arma Giorgi, dado que lo animal interviene de maneras tan obsesivas como determinantes de lo narrado. V(erónica) no solo se encuentra subyugada por la presencia animal en su cercanía, en particular la de los pájaros, abandonada a su contemplación, sino que se volverá animal en numerosos avatares: rata, perro, pulpo gigante. Así es como se produce mediante el periplo de V ese "reordenamiento más vasto" del que habla Giorgi y que permite pensar al animal como artefacto, es decir, como "zona de cruce de lenguajes, imágenes y sentidos desde donde se movilizan los marcos de significación que hacen inteligible la vida como 'humana” (15). En la novela de Docampo, lo animal sirve al propósito, justamente, de subvertir el sistema ordenador que separaba a estos seres de los humanos, al colocarlos en una misma zona y en una fluidez que no pasa por el mero contagio consecuencia del contacto: ya no hay una frontera que separa una piel de la otra, sino que se da ese "continuum orgánico, afectivo, material y político con lo humano" (Giorgi, p.12).

La obra de Mariana Docampo pone en funcionamiento una serie de fuerzas que materializan la posibilidad de pensar a partir de la dinámica de contigüidad para comprender los modos en que es dado imaginar las traslaciones a través de diversos estados (materiales y no tanto). Si el punto de partida es una caída que responde a lo centrípeto, como en el comienzo de $V$ pero también en la figura que cobra forma en el molino de la novela homónima, la fuerza dominante es la centrífuga: dispara a sus personajes, y junto con elles a les lectores, en una multiplicidad de direcciones, algunas más impensadas que otras. La propuesta se va recargando en cada volumen hasta llegar a ese viaje trans-espacial y trans-temporal de V que, en realidad, lo que hace es diseñar una nueva cartografía corporal. La infancia funciona como esas fisuras que resquebrajan una idea sujetada de sujeto. En parte, porque corporiza ese presente absoluto, la presentificación de todo tiempo. También, en la medida en que sigue siendo una instancia que pone en vilo los intentos disciplinadores temporo-espaciales. La teoría queer lo trae una y otra vez a la discusión cuando de pensar la temporalidad se trata. Ofrece, además de una mirada más dinámica y menos esencializante para concebir a estas subjetividades que pululan por allí, entre nosotres, una salida para ese tan deseado reseteo que imagina como solución

Graciela Speranza ${ }^{5}$ y que estamos necesitando para conectarnos de un modo menos lesivo con el resto del universo.

\section{REFERENCIAS}

Agamben, G. (2007 [2001]). Infancia e historia. En Infancia e historia (pp. 5-91). Destrucción de la experiencia y origen de la historia. Trad. Silvio Mattoni. Buenos Aires: Adriana Hidalgo editora.

Ahmed, S. (2015 [2004]). La politica cultural de las emociones. México DF: Universidad Nacional Autónoma de México.

Bourriaud, N. (2018 [2009]). Radicante. Buenos Aires: Adriana Hidalgo.

Chikiar Bauer, I. Entrevista a Mariana Docampo. En la Biblioteca. 14 de octubre 2018.

Deutscher, P. (2019). Crítica de la razón reproductiva. Los futuros de Foucault. Trad. Fernando Bogado. Buenos Aires: Eterna Cadencia.

Docampo, M. (2001). Al borde del tapiz. Buenos Aires: Simurg.

Docampo, M. (2007). Elmolino. Buenos Aires: Bajo la luna.

Docampo, M. (2011). La fe. Buenos Aires: Bajo la luna

Docampo, M. (2014). Tratado del movimiento. Buenos Aires: Bajo la luna.

Docampo, M. (2017).V. Buenos Aires: Bajo la luna.

Edelman, L. (2004). No Future. Queer Theory and the Death Drive. Durham and London: Duke University Press.

Foucault, M. (2010a [1999]). Los anormales. Trad. Horacio Pons. Buenos Aires: FCE.

Foucault, M. (2010b [1977]). Historia de la sexualidad. 1. La voluntad de saber. Trad. Ulises Guiñazú. Buenos Aires: Siglo XXI. 
Freeman, E. (2010). Time Binds. Queer Temporalities, Queer Histories. Durham and London: Duke University Press. Giorgi, G. (2014). Formas comunes. Animalidad, cultura, biopolitica. Buenos Aires: Eterna Cadencia.

Kohan, W. (2007). Infancia, politica y pensamiento. Ensayos de filosofia y educación. Buenos Aires: Del Estante.

Massey, D. (2014). La filosofía y la política de la espacialidad: algunas consideraciones. En L. Arfuch (Comp.), Pensar este tiempo. Espacios, afectos, pertenencias (pp. 99-121). Buenos Aires: Prometeo.

Schérer, R. y Hocquenghem. G. (1979 [1976]). Co-ire. Albúm sistemático de la infancia. Trad. Alberto Cardín. Barcelona: Editorial Anagrama.

Speranza, G. (2017). Cronografias. Arte y ficciones de un tiempo sin tiempo. Barcelona: Anagrama.

Stockton, K.B. (2004). Growing Sideways, or Versions of the Queer Child: The Ghost, the Homosexual, the Freudian, the Innocent, and the Interval of the Animal. En S. Bruhm and N. Hurley (Eds.), Curiouser. On the queerness of children (pp. 277-311). University of Minnesota Press: Minneapolis/London.

Stockton, K.B. (2009). The Queer Child. Or Growing Sideways in the Twentieth Century. Durham and London: Duke University Press.

\section{Notas}

1 Docampo es licenciada en Letras por la Universidad de Buenos Aires. La novela El molino, publicada por Bajo la luna, ganó el segundo premio del Fondo Nacional de las Artes. Es coautora junto con Guillermo Gasió del libro de entrevistas Sara Facio. La foto como pasión (Planeta, 2016). Es coguionista del largometraje Marilyn (Martín Rodríguez Redondo, 2018). Dirige en la editorial Buena Vista, la colección Las antiguas, dedicada a recuperar textos de escritoras argentinas nacidas en el siglo XIX (Salvadora Medina Onrrubia, Elvira Aldao, Emma de la Barra, Juana Manuela Gorriti, etc.). Es fundadora del espacio Tango Queer y una de las organizadoras de un Festival Internacional, experiencia que vuelca en su libro Tango Queer Buenos Aires (Madreselva, 2019).

2 Esta idea de lo "infanceado" es introducida por el filósofo Walter Kohan en su teorización sobre la infancia. Lo piensa a partir de la frase de Heráclito quien, para hablar de un cierto tipo de temporalidad, recurre a la metáfora de un niño que juega (paizon). Lo que quiere decir Heráclito, explica Kohan, es que existe una lógica temporal que no es ni sucesiva ni consecutiva, como sería lo que entendemos por tiempo cronológico, y que se caracteriza por "jugar" con los números. Unir infancia y tiempo implica reconsiderar lo infante a partir de la idea de que, más que un período temporal, la infancia es una relación diferente con el tiempo, marcada por la intensidad. Es lo que los griegos clásicos definían como ese tiempo de Aión (2007, pp. 93-94).

3 Aquí se pone en discusión la idea de esencializar un abordaje de la infancia al modo en que lo hace Giorgio Agamben en su conocido y muy citado ensayo "Infancia e historia", cuyo aporte si bien es central para pensar la experiencia en relación con el lenguaje, acota demasiado lo que sería la experiencia infante (Agamben 2007).

4 Justamente es la idea de "raíz" la que Bourriaud ve como fuente de sufrimiento para los sujetos contemporáneos que viven una experiencia de fluidez inédita y constante. Las raíces, dice Bourriaud, persisten como esos miembros fantasmas que no están, pero hacen subsistir el dolor, afectando una sustancia que ya no existe (2018, p. 23). Por eso él desarrolla la noción de "radicante" a partir de las obras de los artistas contemporáneos, que es un "término que designa un organismo que hace crecer sus raíces a medida que avanza” (p. 24). La ventaja de este concepto es que resulta móvil y fluido, y se refiere a obras que favorecen la multiplicidad de arraigos simultáneos o sucesivos. Es la figura de una condición errante cuya forma se identifica con el trayecto y su modo ético es la traducción.

5 Graciela Speranza abre su texto Cronografias con esta idea que le inspira la obra del artista argentino Adrián Villar Rojas. Se trata de la posibilidad de hacer un "reboot" del tiempo, para superar una temporalidad saturada de presente o sólo pensada como posibilidad cronológica. El término está tomado de la informática y se refiere a reiniciar un sistema operativo luego de un error, para recomenzar el proceso sin los efectos de esa falla, pero sin perder la memoria operativa del sistema (Speranza 2017, pp. 13-15).

\section{BY-NC-SA}

